\title{
8
}

\section{im

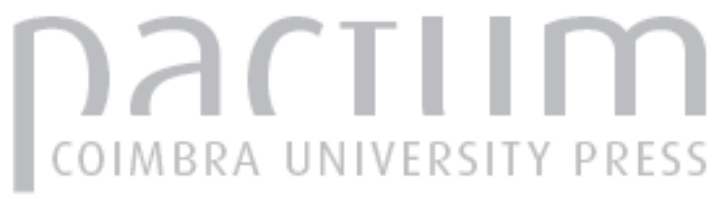

O Chronicon Conimbricense e o arquétipo bíblico de realeza sagrada no Portugal do século XII

\author{
Autor(es): $\quad$ Gouveia, Mário de
}

Publicado por: Imprensa da Universidade de Coimbra

URL persistente:

URI:http://hdl.handle.net/10316.2/43811

DOI:

DOI:https://doi.org/10.14195/2183-8925_36_4

Accessed : $\quad$ 26-Apr-2023 12:18:22

A navegação consulta e descarregamento dos títulos inseridos nas Bibliotecas Digitais UC Digitalis, UC Pombalina e UC Impactum, pressupõem a aceitação plena e sem reservas dos Termos e Condições de Uso destas Bibliotecas Digitais, disponíveis em https://digitalis.uc.pt/pt-pt/termos.

Conforme exposto nos referidos Termos e Condições de Uso, o descarregamento de títulos de acesso restrito requer uma licença válida de autorização devendo o utilizador aceder ao(s) documento(s) a partir de um endereço de IP da instituição detentora da supramencionada licença.

Ao utilizador é apenas permitido o descarregamento para uso pessoal, pelo que o emprego do(s) título(s) descarregado(s) para outro fim, designadamente comercial, carece de autorização do respetivo autor ou editor da obra.

Na medida em que todas as obras da UC Digitalis se encontram protegidas pelo Código do Direito de Autor e Direitos Conexos e demais legislação aplicável, toda a cópia, parcial ou total, deste documento, nos casos em que é legalmente admitida, deverá conter ou fazer-se acompanhar por este aviso.

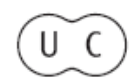



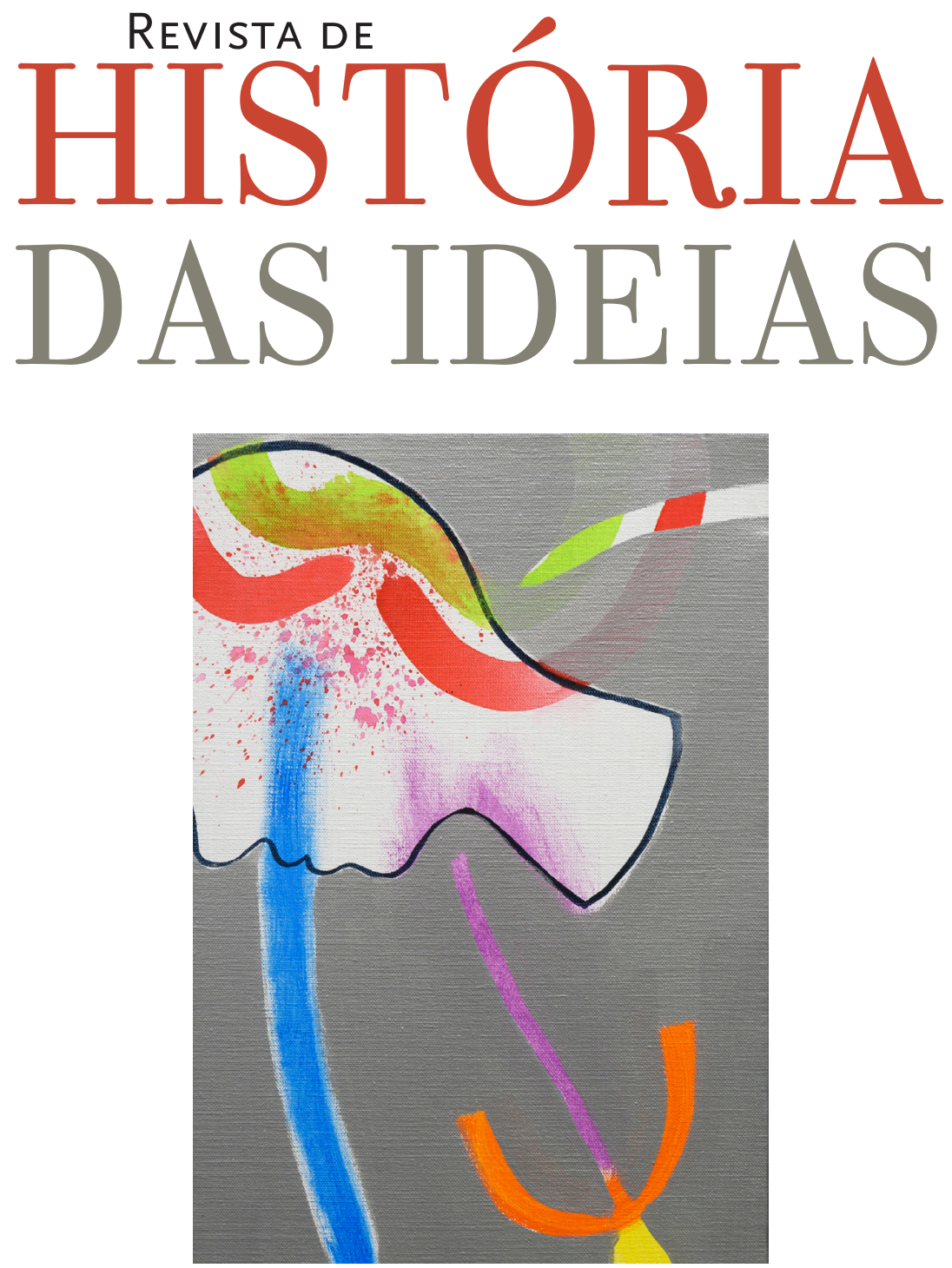

Religiões e Culturas

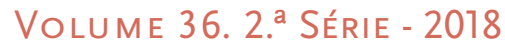




\section{O CHRONICON CONIMBRICENSE \\ E O ARQUÉTIPO BÍBLICO DE REALEZA SAGRADA \\ NO PORTUGAL DO SÉCULO XII \\ THE CHRONICON CONIMBRICENSE \\ AND THE BIBLICAL ARCHETYPE OF SACRED ROYALTY \\ IN $12^{\mathrm{TH}}$ CENTURY PORTUGAL}

\section{MÁRIO DE GOUVEIA}

mariogouveia@campus.ul.pt

Faculdade de Letras da Universidade de Lisboa

Faculdade de Ciências Sociais e Humanas

da Universidade Nova de Lisboa

ORCID: 0000-0003-3943-217X

Texto recebido em / Text submitted on: 27/07/2017

Texto aprovado em / Text approved on: 04/10/2017

\section{Resumo:}

Apresenta-se neste estudo uma breve análise da secção do Chronicon Conimbricense (um manuscrito contendo textos analísticos redigidos no mosteiro de Santa Cruz de Coimbra, nos finais do século XII) alusiva a acontecimentos bíblicos e eclesiásticos. Através do cruzamento desta secção com a parte referente à história de Portugal durante o reinado de D. Afonso Henriques, na qual se procede ao encómio das qualidades guerreiras do rei fundador, constrói-se uma hipótese que sugere que o entendimento das origens do reino pelos cónegos crúzios, à luz dos seus ascendentes bíblicos e eclesiásticos, recupera a teoria 
das seis idades do mundo proposta por Santo Agostinho e cria uma chave de leitura comum na cultura cristã de matriz europeia.

\section{Palavras-chave:}

Mosteiro de Santa Cruz de Coimbra (século XII), analística, Chronicon Conimbricense, realeza sagrada, arquétipo bíblico.

\section{Asbtract:}

In this essay one presents a brief analysis of the section of the Chronicon Conimbricense (manuscript written in the monastery of the Holy Cross of Coimbra in the late 12th century) relating to biblical and ecclesiastical facts. The crossing between this section and the one relating to the history of Portugal during the reign of Afonso Henriques, in which one proceeds to the encomium of the warrior qualities of the founder king, supports the hypothesis that the origins of the kingdom, highlighted by its biblical and ecclesiastical ascendants, are thought according to the theory of the six ages proposed by St. Augustine, therefore creating a common reference within Medieval Christendom.

\section{Keywords:}

Monastery of the Holy Cross of Coimbra (12 ${ }^{\text {th }}$ century), annalistics, Chronicon Conimbricense, sacred royalty, biblical archetype.

Os manuscritos dos textos analísticos latinos que foram redigidos no ambiente monástico do Entre-Minho-e-Mondego nos séculos XI e XII, de que são exemplo algumas obras conhecidas (na sequência dos estudos de José Mattoso e Luís Krus), tais como os Anais de Santo Tirso de Riba de Ave (c. 1079), os Anais de São Salvador de Grijó (c. 1111), os Anais de São Mamede do Lorvão (c. 1118) e os Anais de Santa Cruz de Coimbra I (c. $1169)^{(1)}$, correspondem aos primeiros testemunhos historiográficos que

(1) Estes textos encontram-se publicados em «Chronicon Laurbanense», in Portugaliae monumenta historica a saeculo octavo post Christum usque ad quintundecimum. Scriptores, vol. I. Lisboa: Typis Academicis, 1856, 20; e «Annales Portugalenses Veteres», in Pierre David, 
falam acerca da individualidade política do território onde Portugal se formaria no quadro da cristandade hispânica. Estes textos são unânimes em considerar que a compreensão do sentido da história da região identificada com o condado portucalense, que se foi desvinculando da esfera de influência dos reis e nobres estabelecidos na Galiza e em Leão entre os finais do século XI e as primeiras décadas do XII, devia passar pela recordação de feitos que contribuíssem para a diferenciação desse território e para a criação de uma noção de identidade comum, enraizada em fundamentos concretos e passíveis de ser recordados pela cultura letrada (Krus 2011a; Gouveia 2012).

À data da redação destes textos, a tendência para a comemoração de efemérides ligadas à história dos indivíduos que se destacaram na luta contra o islão e na expansão das fronteiras da cristandade levou à recuperação dos grandes acontecimentos que marcaram a vida política do setor mais ocidental do reino de Leão durante a reconquista cristã (Boissellier 1994), numa cronologia globalmente situada entre os anos de 987 e 1169, isto é, desde a conquista de Coimbra por Muhammad ibn Ab̄̄ 'Āmīr al-Manșūr, ḥājib de Córdova no governo do amīr al-mu'minīn omíada Hishām II al-Mu'ayyad, até à entrada de Geraldo Geraldes, o «Sem Pavor», em Badajoz, já no reinado de D. Afonso Henriques. A sucessão de feitos apontados nestes textos permite-nos compreender as diferentes etapas deste processo e os concomitantes avanços da fronteira que fixaria os limites políticos do reino de Portugal a partir do século XII, ainda que acrescentos às suas primitivas versões latinas tenham prolongado até datas bem mais tardias, como os séculos XIII, XIV e XV - com recurso à língua portuguesa e a letra paleograficamente atribuível aos finais do século XIV ou já a inícios do XV -, a cronologia dos acontecimentos históricos com representação analística.

Esta lógica memorialística inscrevia-se numa tentativa de compreensão da história que acentuava a singularidade de um território à procura de uma identidade própria, por isso se apresentando pouco interessada em descrever os acontecimentos que tinham ocorrido a norte do rio Minho ou a sul do rio Mondego, isto é, fora da jurisdição dos antigos condados constituídos na sequência das presúrias do reinado de Afonso

Études historiques sur la Galice et le Portugal du VI ${ }^{e}$ au XII e siècle. Lisboa-Paris: Livraria Portugália Editora-Société d'Édition «Les Belles Lettres», 1947, 293-299 (AST), 299-302 (AG: dez primeiras notícias) e 308-310 (ASC I). 
III e alargados no decurso das guerras de conquista contra o islão. $\mathrm{Na}$ visão dos religiosos que conceberam aqueles textos, estas regiões do espaço hispânico correspondiam ao território da alteridade, revelando-se assim desnecessárias, como cenários possíveis da ação histórica, para quem procurava demonstrar a suposta individualidade do condado portucalense e do reino de Portugal no contexto da cristandade hispânica, tendo como figura de referência o rei D. Afonso Henriques, o legítimo herdeiro do imperium constituído por Fernando I e Afonso VI de Leão, os conquistadores das cidades de Coimbra e Toledo ${ }^{(2)}$.

Não obstante este facto, alguns manuscritos que se conservaram até aos nossos dias, como o chamado Livro da Noa, códice oriundo do mosteiro de Santa Cruz de Coimbra que incorpora o texto conhecido como Chronicon Conimbricense ${ }^{(3)}$, permitem-nos lançar um olhar crítico sobre esta forma de se conceber a história e extrair dados que ajudam a relativizar o que tem sido afirmado pela historiografia portuguesa, muitas vezes interessada na exaltação, num tom mais ou menos patriótico e apologético (Pinto 2014), dos feitos e dos homens heróicos que personificariam esse natural sentido da nação portuguesa em se afirmar como um país providencialmente destinado ao sucesso histórico. Contrariando esta tendência, a leitura do Chronicon Conimbricense dá-nos conta da existência, nestes textos analísticos, de elementos que universalizam o sentido da história e os inscrevem numa lógica transnacional, apenas compreensível à luz da sua comparação com outros textos análogos redigidos na Hispânia, ou mesmo um pouco por toda a Europa cristã (Bautista 2009). De forma a podermos extrair deste manuscrito algumas ideias que fundamentam esta hipótese, concentraremos a nossa atenção na análise do texto do Chronicon Conimbricense, tal como se encontra publicado por Alexandre Herculano, desde o século XIX, na coleção a que o historiador oitocentista daria a designação, inspirada em modelos

(2) Mattoso 2006. Sobre a projeção desta figura na historiografia portuguesa, Sousa 1996; Mattoso 2000a; Mattoso 2000b; Silvério 2004; Silva 2011. Silvério 1996 analisou com mais detalhe a sua inserção no quadro da analística dos séculos XI e XII.

(3) Este texto encontra-se publicado em «Chronicon Conimbricense», in Portugaliae monumenta historica a saeculo octavo post Christum usque ad quintundecimum. Scriptores, vol. I, fasc. I. Lisboa: Typis Academicis, 1856, 1-5. 
alemães, de Portugaliae monumenta historica a saeculo octavo post Christum usque ad quintundecimum ${ }^{(4)}$.

Nos finais do século XII, isto é, numa altura em que Portugal se afirmava politicamente como um reino independente, os cónegos regrantes de Santo Agostinho do mosteiro de Santa Cruz de Coimbra, centro da chancelaria e panteão dos primeiros reis da dinastia de Borgonha (Cruz 1964; Martins 2003; Gomes 2007) ${ }^{(5)}$, redigiram diferentes textos analísticos compostos por várias secções, de que fazia parte principalmente a relativa à história de Portugal (Gouveia 2012: 199-204), à qual acrescentaram as alusivas à história dos godos (Gouveia 2012: 195-197) e do reino de Astúrias-Leão (Gouveia 2012: 197-199). Ao longo das décadas que se seguiram a esta primeira redação, que deve ter sido terminada pelos finais da década de sessenta ou inícios da de setenta daquele século, hoje conhecida como Anais de Santa Cruz de Coimbra I, os cónegos do mesmo mosteiro ampliaram os relatos iniciais com o acrescento de novas ementas analísticas, redigidas ainda em latim, que alargaram a cronologia dos acontecimentos recordados e comemorados até então pela canónica fundada e patrocinada pelos reis portugueses, criando um texto que viria a ser designado como Anais de Santa Cruz de Coimbra II. Para além das indicações sobre a história do Entre-Minho-e-Guadiana, estes cónegos tiveram o cuidado de apresentar, num dos seus manuscritos paleograficamente atribuível aos finais do século XII ou já aos inícios do XIII - o mesmo que transmitiu até nós o texto que Alexandre Herculano chamou Chronicon Conimbricense ${ }^{(6)}$ - algumas passagens que podem ser entendidas como um preâmbulo à narração histórica propriamente

(4) Na forma como chegou até nós, o Chronicon Conimbricense corresponde ao manuscrito de um texto litúrgico contendo as horas canónicas de noa, às quais se acrescentou uma miscelânea de notícias escritas, em várias épocas, nos três cadernos finais do respetivo saltério de horas diurnas, compiladas entre 1362 e 1365. A primeira parte, redigida em latim, contém notícias datadas ou datáveis de 987 a 1168; a segunda, redigida em português, inclui notícias datadas ou datáveis de 1296 a 1405, com exceção para as relativas às mortes de Inês de Castro (1355) e D. Pedro I (1367), bem como a alusiva à subida de D. Fernando I ao trono (1367).

(5) Gomes 1996 analisou com mais detalhe a elevação deste mosteiro à condição de panteão régio.

(6) Refira-se que parte deste manuscrito serviu também para a redação do Chronicon Lamecense, obra escrita no fólio de guarda de um martirológio-obituário da Sé de Lamego, em 1262. Este texto encontra-se publicado em «Chronicon Lamecense», in Portugaliae monumenta historica a saeculo octavo post Christum usque ad quintundecimum. Scriptores, vol. I, fasc. I. Lisboa: Typis Academicis, 1856, 19-20. 
dita, formado por uma série de ementas relativas àquilo que, hoje em dia, poderíamos designar como arquétipo bíblico de realeza sagrada.

Na mentalidade dos cónegos que redigiram estes anais, a recordação do passado bíblico encontrava paralelos num conjunto de paráfrases escriturísticas com as quais se tornava possível a heroicização, muitas vezes com função ideológica e propagandística, da imagem de D. Afonso Henriques como rei fundador do país que herdara o imperium de Afonso VI e cujas vitórias militares na frente de combate contra o islão eram enaltecidas. Quando, poucos anos após a redação destes primeiros anais, os cónegos atualizaram a sua leitura do passado, promovendo a redação de um texto mais amplo, já com um certo pendor narrativo, destinado sobretudo a descrever as façanhas de D. Afonso Henriques como rei, as relações de intertextualidade com os livros bíblicos tornaram-se mais evidentes, sustentando a construção do arquétipo de herói guerreiro especialmente ungido por Deus e inspirado pela providência divina, segundo o modelo de realeza bíblica consubstanciado na pessoa de David, rei de Israel. Vários livros do Antigo Testamento foram utilizados (Pereira 2001-2002) na criação de uma imagem do reino que se tornara independente e do rei que se afirmara como o privilegiado gládio de Deus na terra e legítimo herdeiro dos principais impulsionadores da reconquista cristã, como que reintegrando Portugal na frente de cultura da Hispânia e, até, da cristandade europeia (Mattoso 2002).

Como é lógico, a ideia de que as origens remotas do reino se deviam compreender com base na recriação de um passado mítico em que os antecedentes bíblicos tinham um lugar privilegiado levou a que estes cónegos incluíssem nos seus anais referências a diversos acontecimentos extraídos não só do Antigo, mas também do Novo Testamento, bem como da tradição instituída pela igreja nos primeiros séculos da sua história. À data da cópia para o manuscrito que o fixou até à atualidade, o Chronicon Conimbricense passou a dispor de uma secção, formada por um conjunto de ementas avulsas, em que se mencionava o nascimento de Jesus Cristo, a decapitação de São João Baptista, a morte dos apóstolos São Tiago e São Pedro, dos mártires São Ciprião, São Julião, Santa Basilissa e São Vicente e do confessor São Martinho. Antes de concluírem esta secção, os mesmos cónegos evocaram ainda, possivelmente sob inspiração da teoria proposta por Santo Agostinho na obra De Catechizandis Rudibus (Lopes 2012: 100-103), todas as principais etapas da criação do mundo por Deus, dividindo-as num conjunto de seis idades marcadas 
por acontecimentos fundamentais da história dos grandes patriarcas, profetas e reis de Israel: de Adão ao dilúvio, do dilúvio a Abraão, de Abraão ao êxodo, do êxodo a David, de David ao cativeiro da Babilónia e, por fim, do cativeiro da Babilónia ao nascimento de Jesus Cristo.

Estes acontecimentos, devidamente categorizados como marcos histórico-teológicos, foram anotados pelos compiladores dos anais e associados aos anos em que supostamente teriam ocorrido, perfazendo, no total, 5199 anos, isto é, um longo espetro cronológico de mais de cinco milénios, materializando a ideia de que a história de Portugal tinha antecedentes mais remotos do que se poderia pensar à partida. A história de Portugal e de D. Afonso Henriques, vista na ótica de uma construção providencialista, deve, pois, ter sido encarada pelos cónegos do mosteiro de Santa Cruz de Coimbra como uma espécie de consumação das seis idades do mundo já preconizadas pelas tradições escriturística, de matriz judaico-cristã, e patrística. À data da redação desta secção dos anais crúzios, a livraria do mosteiro incluía a obra de Santo Agostinho (Nascimento 1997) e os cónegos serviram-se dela para a elaboração deste texto.

Na conceção dos cónegos que escolheram escrever a história do reino de Portugal à luz dos seus antecedentes bíblicos, o relato da sucessão de acontecimentos contados nestes anais tinha talvez como objetivo associar a história de uma casa dinástica de formação recente à dos patriarcas, profetas e reis de Israel e à dos santos da igreja cujo papel estava vinculado à realização dos desígnios salvíficos de Deus, através de Jesus Cristo. De entre todos, o destaque recaiu sobre os apóstolos e os mártires, porque estes deviam ser vistos como aqueles que, com o seu exemplo de vida e anúncio da fé, tinham dado um testemunho imprescindível para a construção de uma sociedade que se digladiava com a ameaça externa, à qual importava resistir tal como aqueles santos tinham resistido no passado.

Este facto merece, quanto a nós, um destaque particular: em primeiro lugar, porque indica que o Chronicon Conimbricense é um monumento historiográfico em que se associa de forma clara a história nacional à história universal (Lay 2011: 123-127); por outro, porque sugere que os responsáveis por esta associação tinham talvez em mente a ideia de que Portugal, enquanto reino, fazia parte de uma longa cadeia genealógica de reinos com mais de cinco mil anos de história, vistos como uma es- 
pécie de antepassados simbólicos de uma monarquia que, devido à sua condição emergente, procurava novas fontes de legitimidade política.

Tal associação de ideias não era, na época, uma característica exclusiva da analística ligada às origens do reino de Portugal. Na Galiza, em Leão ou em Castela - bem como fora das fronteiras da Hispânia cristã -, vários outros anais foram redigidos, também em latim ou contendo já perícopes em línguas vernáculas, em que o sentido local e regional da história (Viana 1993; Pereira 2003: 15-32; Pereira 2005) foi posto em paralelo com o da história universal de Deus e da Igreja, como que criando uma leitura de feitos que acentuou as origens transnacionais dos reinos que nasciam na Europa medieval e que mantinham entre si um denominador comum: a sua filiação na cristandade ${ }^{(7)}$, isto é, numa entidade cuja importância histórica se situava além das fronteiras políticas de cada país. Na ótica dos religiosos que redigiam estes anais - bem como, naturalmente, na dos cónegos que trabalhavam no scriptorium do mosteiro de Santa Cruz de Coimbra poucos anos após a morte de D. Afonso Henriques -, era como se a história devesse ser compreendida como algo de inscrito no plano das realizações salvíficas de Deus para o Homem, da criação do mundo à encarnação do Verbo, mas pudesse ser também entendida em função de um símbolo capaz de integrar essa história, ainda de caráter local e regional, na de uma entidade fundada em matrizes religiosas.

Numa data que não poderá ir muito além dos finais do século XII, a tendência dos anais crúzios para alargar a perspetiva nacional à perspetiva universal contribuiu para o surgimento de uma obra historiográfica com um sentido mais abrangente. A inclusão de uma secção alusiva a acontecimentos bíblicos e eclesiásticos inscreveu-os no mais alargado plano da cultura cristã de matriz europeia, isto é, numa cultura cujo significado radicava na compreensão de que Portugal - sancionado pelo papa Alexandre III como reino independente em 1179, data da outorga da bula Manifestis Probatum - gravitava em torno de uma órbita transfronteiriça (Buresi 2001; Buresi 2004).

Depois da cópia do texto para o manuscrito que o conservou até à atualidade, o Chronicon Conimbricense não voltou mais a ser utilizado como fonte para a reconstituição do passado na tradição historiográfica que se seguiu às primeiras experiências analísticas crúzias, apesar

(7) Arduini 1984; com análise sobre o caso hispânico em Benito Ruano 1952; Huete Fudio 1994; Bautista 2009. 
de estas terem sido alvo de pontuais acrescentos ao longo dos séculos XIII e XIV (Moreira 2010). Embora o texto tenha sido recuperado por alguns autores ainda mais tardios, nos séculos XVI, XVII e XVIII, para justificar um conjunto de visões apriorísticas sobre o passado ${ }^{(8)}$, a sua divulgação no meio científico português só se tornou possível a partir da transferência do manuscrito autógrafo para Lisboa por José Manuel da Costa Basto, algures nos meados do século XIX, e da publicação do texto por Alexandre Herculano, sob os auspícios da Academia das Ciências de Lisboa, no quadro de uma Europa marcada pela emergência do nacionalismo e do positivismo (Silva 2015) e interessada em encontrar nos textos antigos e medievais as supostas raízes da sua visão idealizada da história ${ }^{(9)}$.

No caso português, o quadro de referências mentais dos cónegos que redigiram o Chronicon Conimbricense, ao contrário do que pretendeu durante anos a historiografia, não se pode compreender sem se ter em conta a sua integração na cultura cristã de matriz europeia, que dá ao texto uma dimensão mais universal e capaz até de questionar o sentido exclusivamente nacional da fronteira que se foi formando em Portugal a partir da primeira metade do século XII. No fundo, este texto pertence a uma série de memórias que condensam a ideia de que a história do reino medieval, ainda que individualizável criticamente, não se pode dissociar de referências mais universais e abrangentes, suscetíveis de se socorrer de uma linguagem simbólica comum e de criar nos seus leitores uma espécie de chave de identificação que está para além do que é puramente local e regional. A leitura do Chronicon Conimbricense pode, por esta ordem de razões, constituir-se como um exercício necessário à revisão dos tópicos historiográficos utilizados para se compreender a história da cultura medieval portuguesa, ajudando-nos, nos seus aspetos mais inovadores, a lançar um olhar crítico à forma como, nas últimas décadas, se tem reconstituído a história de Portugal e dos restantes países da Europa (Valcárcel 2005).

(8) Tarrío 2006; Krus 2011b (cf. Montenegro \& Castillo 2009).

(9) Atualmente, o manuscrito autógrafo em pergaminho, escrito em latim e português, conserva-se, sob a forma de um livro composto por vinte e nove fólios, em formato 295 x 215 x $20 \mathrm{~mm}$, no fundo do mosteiro de Santa Cruz de Coimbra do Arquivo Nacional da Torre do Tombo, em Lisboa, com o título Livro da Noa e cota Cónegos Regulares de Santo Agostinho, Mosteiro de Santa Cruz de Coimbra, liv. 99 (cota antiga CF 83; Coleção Costa Basto, n. ${ }^{\circ} 43$ ). 


\section{Bibliografia:}

\section{Textos medievais}

«Annales Portugalenses Veteres», in Pierre David, Études historiques sur la Galice et le Portugal du VI ${ }^{e}$ au XII siècle. Lisboa-Paris: Livraria Portugália Editora-Société d'Édition «Les Belles Lettres», 1947, 257-340.

«Chronicon Conimbricense», in Portugaliae monumenta historica a saeculo octavo post Christum usque ad quintundecimum. Scriptores, vol. I, fasc. I. Lisboa: Typis Academicis, 1856, 1-5.

"Chronicon Lamecense», in Portugaliae monumenta historica a saeculo octavo post Christum usque ad quintundecimum. Scriptores, vol. I, fasc. I. Lisboa: Typis Academicis, 1856, 19-20.

«Chronicon Laurbanense», in Portugaliae monumenta historica a saeculo octavo post Christum usque ad quintundecimum. Scriptores, vol. I. Lisboa: Typis Academicis, 1856, 20.

\section{Estudos}

Arduini, Maria Lodovica (1984). «Per una interpretazione storiografica della 'Christianitas' medievale (secoli XI e XII). Le categorie del profetico e del simbolico», Bullettino dell'Istituto Storico Italiano per il Medio Evo e Archivio Muratoriano, 91: 1-113.

Bautista, Francisco (2009). «Breve historiografía. Listas regias y anales en la Península Ibérica (siglos VII-XII)», Talia dixit, 4: 113-190.

Benito Ruano, Eloy (1952). «La historiografía en la Alta Edad Media española. Ideología y estructura», Cuadernos de historia de España, 17: 50-104.

Boissellier, Stéphane (1994). «Réflexions sur l'idéologie portugaise de la Reconquête. XII $-X I V$ e siècles», Mélanges de la Casa de Velázquez, 30 (1): 139-165.

Buresi, Pascal (2001). «Nommer, penser les frontières en Espagne aux XI ${ }^{\mathrm{e}}$ -XIII ${ }^{\mathrm{e}}$ siècles», in Carlos de Ayala Martínez, Pascal Buresi \& Philippe Josserand (eds.), Identidad y representación de la frontera en la España medieval (siglos XI-XIV). Madrid: Casa de Velázquez - Universidad Autónoma de Madrid, 51-74.

«- (2004). La frontière entre Chrétienté et Islam dans la Péninsule Ibérique. Du

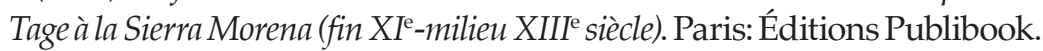


Cruz, António (1964). Santa Cruz de Coimbra na cultura portuguesa da Idade Média. Porto: Biblioteca Pública Municipal do Porto.

Gomes, Saul António (1996). «Os panteões régios monásticos portugueses nos séculos XII e XIII», in 2. ${ }^{\circ}$ Congresso histórico de Guimarães, vol. 4: Sociedade, administração, cultura e igreja em Portugal no séc. XII. s.l.: Câmara Municipal de Guimarães-Universidade do Minho, 281-295. « » (2007). In limine conscriptionis. Documentos, chancelaria e cultura no mosteiro de Santa Cruz de Coimbra (séculos XII a XIV). Viseu: Centro de História da Sociedade e da Cultura - Palimage Editores.

Gouveia, Mário de (2012). «O essencial sobre a analística monástica portucalense (séc. XI-XII)», Lusitania sacra. Revista do Centro de Estudos de História Religiosa, 25: 183-226.

Huete Fudio, Mario (1994). «Fuentes menores para el estudio de la historiografía latina de la Alta Edad Media hispánica (siglos VII-X)», Medievalismo. Boletín de la Sociedad Española de Estudios Medievales, 4: 5-26.

Krus, Luis (2011a). «A produção do passado nas comunidades letradas do Entre Minho e Mondego nos séculos XI e XII - As origens da analística portuguesa», in A construção do passado medieval. Textos inéditos e publicados. Lisboa: Instituto de Estudos Medievais da Faculdade de Ciências Sociais e Humanas da Universidade Nova de Lisboa, 235-258. « - (2011b). «Tempo de Godos e tempo de Mouros. As memórias da Reconquista», in A construção do passado medieval. Textos inéditos e publicados. Lisboa: Instituto de Estudos Medievais da Faculdade de Ciências Sociais e Humanas da Universidade Nova de Lisboa, 93-113.

Lay, Stephen (2011). «Escribiendo la reconquista. La consolidación de la memoria histórica en el Portugal del siglo XII», Studia historica. Historia medieval, 29: 121-143.

Lopes, Eliseu Teixeira (2012). A pedagogia catequética segundo o De Catechizandis Rudibus de Santo Agostinho. Lisboa (Edição policopiada da dissertação de Mestrado apresentada à Faculdade de Teologia da Universidade Católica Portuguesa).

Martins, Armando Alberto (2003). O mosteiro de Santa Cruz de Coimbra na Idade Média. Lisboa: Centro de História da Universidade de Lisboa.

Mattoso, José (2000a). «As três faces de Afonso Henriques», in Obras completas, vol. 1: Naquele tempo. Ensaios de história medieval. s.l.: Círculo de Leitores, 469-484. 
«-» (2000b). «A nova face de Afonso Henriques», in Obras completas, vol. 1: Naquele tempo. Ensaios de história medieval. s.l.: Círculo de Leitores, 485-500.

«-» (2002). «Cluny, Crúzios e Cistercienses na formação de Portugal», in Obras completas, vol. 8: Portugal medieval. Novas interpretações. s.l.: Círculo de Leitores, 79-93.

«-» (2006). D. Afonso Henriques. Lisboa: Círculo de Leitores.

Montenegro, Julia \& Arcadio del Castillo (2009). «The Alfonso II document of 812, the Annales Portugalenses Veteres and the continuity of the Visigothic kingdom of Toledo as the kingdom of Asturias», Revue belge de philologie et d'histoire, 87: 197-214.

Moreira, Filipe Alves (2010). «A historiografia régia portuguesa anterior ao conde de Barcelos», in Maria do Rosário Ferreira (ed.), O contexto hispânico da historiografia portuguesa nos séculos XIII e XIV. Em memória de Diego Catalán. Coimbra: Imprensa da Universidade de Coimbra, 33-51.

Nascimento, Aires Augusto (1997). «O scriptorium de Santa Cruz. Momentos da sua história», in Catálogo dos códices da livraria de mão do mosteiro de Santa Cruz de Coimbra na Biblioteca Pública Municipal do Porto. Porto: Biblioteca Pública Municipal do Porto, LXIX-XCV.

Pereira, Armando de Sousa (2001-2002). «Motivos bíblicos na historiografia de Santa Cruz de Coimbra dos finais do século XII», Lusitania sacra. Revista do Centro de Estudos de História Religiosa, 13-14: 315-336. « - » (2003). Representações da guerra no Portugal da Reconquista (séculos XI-XIII). Lisboa: Comissão Portuguesa de História Militar.

«- (2005). «A Reconquista entre o Douro e o Tejo nos anais monásticos dos séculos XI e XII», in Mário Jorge Barroca \& Isabel Cristina F. Fernandes (eds.), Muçulmanos e Cristãos entre o Tejo e o Douro (sécs. VIII a XIII). Palmela: Câmara Municipal de Palmela-Faculdade de Letras da Universidade do Porto, 103-110.

Pinto, Olga Maria Pereira Ribeiro Martins (2014). Educação e ideologia. Portugal, pátria de heróis. A figura histórica em contexto educativo (19261974). Lisboa (Edição policopiada da tese de Doutoramento apresentada à Faculdade de Ciências Sociais e Humanas da Universidade Nova de Lisboa).

Silva, José Alberto Teixeira Rebelo da (2015). A Academia Real das Ciências de Lisboa (1779-1834). Ciências e hibridismo numa periferia europeia. 
Lisboa (Edição policopiada da tese de Doutoramento apresentada à Faculdade de Ciências da Universidade de Lisboa).

Silva, Tiago João Queimada e (2011). As metamorfoses de um guerreiro. Afonso Henriques na cronística medieval. Coimbra (Edição policopiada da dissertação de Mestrado apresentada à Faculdade de Letras da Universidade de Coimbra).

Silvério, Carla Alexandra Serapicos (1996). «A imagem da realeza na analística medieval portuguesa dos séculos XI e XII», in $2{ }^{\circ}$ Congresso histórico de Guimarães, vol. 3: D. Afonso Henriques na história e na arte. s.1.: Câmara Municipal de Guimarães - Universidade do Minho, 33-40.

« - (2004). Representações da realeza na cronística medieval portuguesa. A dinastia de Borgonha. Lisboa: Edições Colibri - Faculdade de Ciências Sociais e Humanas da Universidade Nova de Lisboa.

Sousa, Bernardo Vasconcelos e (1996). «D. Afonso Henriques nas primeiras crónicas portuguesas», in 2. ${ }^{\circ}$ Congresso histórico de Guimarães, vol. 3: D. Afonso Henriques na história e na arte. s.l.: Câmara Municipal de Guimarães-Universidade do Minho, 21-31.

Tarrío, Ana María (2006). «La memoria de los Godos en João de Barros (Geographia d'Entre-Douro-e-Minho)», in Aires A. Nascimento \& Paulo F. Alberto (eds.), IV Congresso internacional de Latim medieval hispânico. Actas. Lisboa: Centro de Estudos Clássicos, 889-904.

Valcárcel, Vitalino (2005). «La historiografía latina medieval de Hispania, un quehacer de la filología latina hoy», Historia. Instituciones. Documentos, 32: 329-362.

Viana, Mário (1993). «A memória regional na analística portuguesa dos séculos XI e XII», Estudos medievais, 10: 59-78. 